\title{
Mountain roads development in Nepal: engineering geological concerns
}

\author{
Birendra B. Deoja \\ Ministry of Works and Transport, His Majesty's Government of Nepal, Babar Mahal, Kathmandu, Nepal
}

\section{ABSTRACT}

Road construction in the mountainous regions of Nepal has not only added to the road building experience in the rugged mountain terrain but also created awareness that development of linear infrastructure in the mountainous regions requires multidisciplinary approach from social, economic, engineering, environmental, and biotechnical considerations besides substantial engineering-geological inputs. This paper tries to provide a brief account of the practices and developments in mountain-specific planning and management of infrastructure on the basis of experiences from Nepal.

\section{INTRODUCTION}

Nepal may be regarded as "a museum of mountain roads" due to the fact that many countries such as China, Germany, India, Japan, Switzerland, the United Kingdom, and the United States of America have struggled for one or two decades since 1950 with the rugged and young mountain ranges of the Himalaya to construct roads for the development of Nepal. International consultants have acquired considerable experience over here through their involvement in the road programmes under credit assistance of multilateral agencies such as the World Bank and the Asian Development Bank. The cost and time of road construction, the problems of landslides, the maintenance burdens, and the level of services offered by these roads have aroused serious concerns on the technologies and the degree of social, economic, and environmental impacts. These have contributed to development of concepts and approaches specific to the mountain terrain and environment.

It was increasingly realised that traditional civil engineering is oriented to the plain area and the transported soils. The linear infrastructure in the mountainous regions is subject to a much higher degree of variability, temporally and spatially, in the properties of soil, rock, slope, and drainage. Cost-effective and environment-friendly engineering of the infrastructure in the mountainous slopes requires that these variables and uncertainties be recognised and understood at all stages of the project cycle (Deoja 1994). Development aspirations of the people, the popular decision-making culture of the politicians, the technological biases of the engineers and professionals, and the perpetual resource constraints are the factors acting either jointly or severally so that they ultimately result in a mismatch leading to either the misuse of resource or degradation of the environment or both. This can only be addressed by the development of a systematic and comprehensive approach to mountain-specific infrastructure planning and engineering. Understanding and application of the knowledge of geology, geomorphic processes, and engineering geological properties of rocks and soils is fundamental to the development of such an approach.

\section{HISTORY OF MOUNTAIN ROAD DEVELOPMENT IN NEPAL}

The Tribhuvan Rajpath (TRP) is a $131 \mathrm{~km}$ long singlelane road linking the Kathmandu Valley with the southern plains at Hetaunda. It was the first major road-engineering project in the history of Nepal. The Indian Army built it during 1950-1956. It basically follows hill contours and is primarily a cut-type road formation in the Mahabharat Range. This road is characterised by narrow width, tortuous bends, steep gradients, and stressful 4 to 5 hour journey from $1,200 \mathrm{~m}$ above mean sea level (msl) to 2,100 $\mathrm{m}$ above msl and down to $500 \mathrm{~m}$ above msl. The problems of landslides and road washouts on this road are believed to be comparatively less than on the other trunk roads. Nevertheless, the rainfall of 1993, thirty-seven years after the completion of the road, resulted in extensive landslides and washouts forcing the road closure for more than a month.

The Arniko Rajmarg (Kodari Highway) is a $114 \mathrm{~km}$ long double-lane road from Kathmandu to the Chinese border in the north built by the Chinese during 1962-1970. This is also a primarily cut section mostly following river valleys and passing through the Mahabharat Range and High Mountains in the Midlands. Washouts of about 25 per cent of road length every five to ten years from high rainfall and outburst floods are the characteristics of this road.

The Siddhartha Rajmarg (Sunauli-Pokhara Road) is a $175 \mathrm{~km}$ long double-lane road built by the Central Public Works Department of the Government of India during 19631970. It also follows hill contours and is primarily a cut formation in the Mahabharat and Siwalik Ranges. It has a better geometry than the TRP. It passes through the Main Boundary Thrust (MBT) for some stretch and consists of perpetual landsliding spots.

The Prithvi Highway is a $175 \mathrm{~km}$ long double-lane road from Naubise to Pokhara built by the Chinese engineers and technicians under the Chinese grant assistance programme during 1966-1974. It is also a double-lane road primarily in cut section in the Mahabharat Range and the High Mountains following river valleys for most of the alignment. 
The turning radius is varying from sharp bends at a difficult terrain to smooth curves at easy sections. Debris flow, bank erosion, and bridge washouts cause considerable damage to the road once in 4 to 5 years.

The Dhangarhi-Dandeldhura Highway is a $140 \mathrm{~km}$ long road in the far western hills of Nepal built entirely by the Nepalese engineers during 1966-1980 under the grant assistance and advisory technical support of the United States of America. It is a typical example of slope disturbances from indiscriminate hill cutting and side casting. The high cutting in the steep slopes of the fragile Siwalik Ranges and rugged Mahabharat Range gave rise to the problem of massive landslides and slope disturbances over a wide area of influence uphill and downhill.

The $110 \mathrm{~km}$ long Lamosangu-Jiri Road was constructed by the Swiss during 1975-1984. This is a single-lane, cut and fill balance-type of road with a low cut height through the Mahabharat and the High Mountain Ranges.

The $50 \mathrm{~km}$ long, double-lane Dharan-Dhankuta Road was built by the British during 1976-1981. This is also a cut and fill balance-type of road through the Mahabharat Range with extensive retaining structures and slope stabilisation measures.

Many other roads have been constructed in the mountainous regions of Nepal during the 1970s and 1980s. By now, there is a total of about $6,000 \mathrm{~km}$ of mountain roads out of a total of about $11,000 \mathrm{~km}$ roads in Nepal. But the roads described above constitute the vital network and foundation of development of mountain-specific engineering of roads and other types of infrastructure in Nepal.

\section{IMPACTS AND CONCERNS}

The landslide problems caused by high cut sections for wider roads in the mountainous regions aroused serious concerns on the road stability, maintenance burdens, and environmental degradation. These were reflected in the alignment selection and designs of the Swiss- and the British-funded roads in Nepal in the 1970s and 1980s.

The failure of the Tinau bridge, along the East-West Highway in the Siwalik Range of Western Nepal in 1978 due to a deep rotational landslide on the right bank of the river resulting in the heaving up of the bridge foundations, shear failures of the substructure and superstructure, and washout of the bridge is an example of the problems from inadequate investigations of existing and predated instabilities in and around the proposed site of the structure or road location.

Engineering geological study of the DhangarhiDandeldhura Road, 12 years after the start of construction, in 1978 by Eugene Kojan, an Engineering geologist from the U. S. Forest Service, was a landmark in arousing serious concerns on the indiscriminate cutting without regards to engineering geological and geotechnical investigations of road locations and designs. The desire to achieve a two lane wide road with a minimum of $30 \mathrm{~m}$ radius curves at low cost and short time led to cutting as high as $50 \mathrm{~m}$ triggering off several landslides of 5000 to 50,000 cubic $\mathrm{m}$ in volume and slope disturbances for more than $300 \mathrm{~m}$ downhill. Landslides affected about $15 \%$ of the entire alignment for several years. Indiscriminate cutting and blasting created major instabilities even in the otherwise stable ridge sections of the road alignment. A two-year landslide stabilisation programme costing about US\$ 3 million attempted to stabilise the humaninduced landslides by using self-draining gabion buttresses, counterfort drains, and peripheral drains, but the success was more symbolic than overwhelming. Large-scale use of gabion walls for road structures, transfer of skill to knit gabion wire mesh at the local level, and awareness against indiscriminate hill cutting were significant contributions of this project.

High gabion walls were constructed along the $50 \mathrm{~km}$ long Dharan-Dhankuta Road built under the British assistance in the Siwaliks and the Mahabharat Range. The soft sedimentary rocks as well as quartzites, phyllites, and gneisses are prone to landsliding of cut slopes daylighted without surface and subsurface drainage. Debris flow, mudflow, and subsidence are some problems in this road. Several non-vegetative surface covering techniques were tried to stabilise the cut slopes in this road without much success. However, significant knowledge and practical experience was gained in the field of vegetative stabilisation of roadside slopes from the works in this road.

An abrupt lowering by $9 \mathrm{~m}$ of the Charnawati riverbed in 1987 in the Lamosangu - Jiri Road northeast of Kathmandu, leading to stabilisation works amounting to 11 million Swiss Franks, is an example of the severe problems of bed erosion and side slope failures due to cloud bursts and sudden high floods in a thick deposit of colluvium in the High Mountains. Modern engineering techniques, such as the geophysical investigations and drilling, network of subsurface drains and horizontal drilled drains, soil anchors, tetrapods, and extensive check dams, for the stabilisation of the slopes and the riverbed were applied to a considerable extent in this road project. These experiences were utilised successfully in the rehabilitation of the Arniko Rajmarg during 1992 to 1994 under the Road Flood Rehabilitation Project (RFRP) designed to rehabilitate the damages of the 1987 floods to this river route highway.

Road failures and washouts as a result of heavy monsoon rains during fifteen years (1979-1993) resulted in the rehabilitation works amounting to 2.5 billion rupees in Nepal.

The failure of a $30 \mathrm{~m}$ span bridge over the Seti River, Pokhara, along the Prithvi Highway, took place in 1991 due to a slip failure from undercutting of the bank, made up of a high bearing capacity conglomerate, at more than $50 \mathrm{~m}$ below the foundation in less than 25 years of the bridge life suggests that foundation design of major bridges needs to be investigated the geological formation, landslide triggers, and vulnerability of material failure much below the apparent foundation. 
Uncontrolled blasting without knowledge of rock type, degree of jointing, fracturing, weathering, and joint spacing has triggered off massive hill instabilities in many roads of Nepal. Similarly, engineers have committed blunders by blasting and excavating sound rocks and replacing it with cement masonry in order to make room for the foundation of conventional retaining walls while it could easily have been done by bench cutting and masonry filling only. Another mistake of engineers are frequently and almost invariably making is the selection of a front battered retaining wall and increasing the height of retaining wall unnecessarily in the steep slopes. This has increased the quantity of retaining wall by about three times and increased the cost and the risk to a great extent. Lack of knowledge in slope stability evaluations have often led to either the cutting of the toe of slides or erecting retaining walls on the head of the landslide.

The chain of events triggered by landslides have increased the annual sediment yield of watershed, stream aggradation, and accelerated stream bank erosion and secondary landslides. The net impact is the destruction of irreplaceable agricultural land in the valleys and the plains downstream.

Thus, roads have often turned out to be a wasted investment creating ugly scars in the environment and taking away the precious land, the lifeline of the local people, rather than agent of change and prosperity. Many mountain roads have been completely abandoned after full or partial completion, not only in Nepal but also in other parts of the world.

What are the impacts in terms of traffic levels and socioeconomic betterment in the area around the influence of these roads? What are the implications of costs of these roads requiring investments of 5 to 30 million rupees per $\mathrm{km}$, that is about 0.01 to 0.04 per cent of the annual budget of the nation for every km of road, in a developing country such as Nepal?

The traffic in the TRP even after 43 years of operation is only around 83 AADT. Almost all the 2000 to 3000 AADT of traffic prefers to use the $90 \mathrm{~km}$ longer Naubise - MuglingNarayanghat - Hetaunda Road. The traffic in the Lamosangu - Jiri Road, Dharan - Dhankuta Road, and the Dhangarhi Dandeldhura Road is 243, 399, and 191 after 15 years, 18 years, and 19 years of completion, respectively. The Siddhartha Rajmarg is having the traffic of 545 AADT after three decades of completion.

\section{KEY CONCERN}

Planning of mountain roads cannot be sound unless development paradigms are clear. Roads are believed to be automatic vehicles of social justice and development. But the history of traffic levels in the completed roads and the level of economic activities in the area around the road even after two to three decades of provision of roads in the remote mountainous regions of Nepal are not witnessing the universal applicability of this theory. This is evident from the overall weighted scores of development indicators prepared by ICIMOD for the 75 districts of Nepal in 1997. The study shows that the districts without road connection such as Sankhuasabha, Khotang, Bhojpur, Solukhumbu, Mustang, Manang, Myagdi are having total weighted scores of $59,46,48,42,69,74$, and 58 respectively out of the maximum score of 75 , whereas some districts having road connection since more than a decade are having very low scores. Doti, Baitadi, Rolpa, Dandeldhura, Rautahat, Sallyan, Mahottari are such districts having scores of $6,13,12,15$, 14,16 , and 17 , respectively. Roads are no doubt instrumental in breaking the barrier of isolation but this itself is not synonymous to development or quality of life.

The user cost of porterage or transportation by mule is 150 to 300 times that of truck under ideal conditions, but the life cycle cost including the agency cost does not result in such a margin of saving due to high initial cost, delayed benefits, and tortuous and isolated terrain between the origin and destination.

The key question, therefore, is: how to reduce the initial cost of investment on infrastructures and at the same time improve the quality of life of the people living in remote mountain villages? Subsidy is not the answer. Creating economic activities and conditions of sustainability is not easy either, since roads are unlikely to be effective unless there is simultaneously an investment two to three times that of the road in the influence area of each $\mathrm{km}$ of road. Air transport and tourism is one of the options to create economic activities with private investments. But minimum road accessibility at lowest possible investment is often unavoidable for local production and distribution of food and agricultural inputs. This calls for techniques to align the road and construct it such that the risk management is affordable. Assessments of geological and geomorphic hazards, route location by avoiding the hazards, road designs without aggravating the hazards, and inexpensive countermeasures to modify the residual hazards are, therefore, unavoidable to ensure least risks to the structure and the environment at minimum initial investment. To quote Kojan (1978), " the juxtaposition of unstable slopes and the ubiquitous presence of man and his works, such as in Nepal, produces an extraordinarily high level of hazard requiring an unusually sensitive matching of engineering works to the terrain and its natural processes."

\section{LESSONS LEARNT}

Planning and management of infrastructure in the mountainous regions are not only engineering issues but also a socio-economic problem compounded by geological and geomorphological problems. Proper engineering of a linear infrastructure in the hills and mountains is therefore incomplete without awareness, at the national level, on geological hazards and development paradigms appropriate to resource endowment. At the project level, minimum knowledge of socio-economics, geology, and slope stability is essential. Hazard assessment before selecting route 
alternatives, risk assessment, and management before finalising the designs, and rigorous slope stability and landslide analysis, and control before modifying major hazards during constructions and maintenance are essentials of infrastructure engineering in the mountains. The engineering that deals with all these concerns in an integrated manner is Mountain Risk Engineering.

\section{MOUNTAIN RISK ENGINEERING}

Structures in the mountainous terrain are subject to instabilities from ground movement due to the slope, the gravitational pull, the earthquakes, erosion, and pore water pressure. The structure on slope, as compared to the structure on plains, is subject to considerable magnitude of the horizontal forces from lateral earth pressure, slip failures, or slope movements due to disturbances up slope or down slope beyond the location of the structure, and the variations in the magnitude of the destabilising forces over time during the design life of the structure due to the geomorphological processes. The traditional engineering and geotechnical considerations in the plain areas normally deal with the bearing capacity of the soil, the foundation settlement, and the shearing strength of the soil as characterised by angle of internal friction, cohesion, and rate of consolidation for transported soils. The strength characteristics of residual soils formed by in situ weathering are not yet well understood. The variation in the forces and material strengths due to geomorphic process beyond the location of the structure is not of concern in the plain areas. In short, the structures in the mountainous terrain have to be designed for the dynamic conditions over the intended life in contrast to the conventional practice of static conditions of forces and material strengths. The problem is not just the design of a stable structure but a structure that does not cause the destruction of the precious land below from soil loss and sedimentation. The hazard assessment attempts to understand the effect of geomorphic processes, quantify and communicate it in simple terms, and assist the designer to allow for the worst case of forces and strengths subjected to the structure for a given period of time. It is not as simple as it may sound, but a feel of these factors definitely assists the engineer to have more confidence in his design. The mountain environment is so sensitive to the natural and man-made processes that any structure built on it without reasonable understanding of the impacts to and from the structure will create problems for itself and the environment, and hence cannot be said to have been properly engineered. Therefore, hazard and risk assessment is required to:

understand instabilities from geomorphic processes,

assess engineering geological properties of the slope forming materials,

quantify and communicate uncertainties,

assess the damages from existing or potential events,

understand impacts to and from the environment, increase the accuracy of cost estimates at various project cycles,
- understand total costs over a period of time,

- optimise investment efficiency,

- develop reliable designs, and

- use it as a decision-making tool.

As the geomorphic processes in the mountain slopes are dynamic, the structures built on these slopes on the basis of design against the forces at a particular time may not withstand the forces after some time in future. The instabilities are not generally of concern unless they threaten the life and property of human beings. The potential threat of ground failure is the hazard. And the potential loss of life and property is the risk. One would not normally worry about hazard and the ground failures if it does not affect the life and property, but if we are infringing upon the nature and would like to be protected from losses, then we need to understand the geological processes, the extent of temporal and spatial instabilities, and the extent of damage that we can tolerate. We have to assess the hazard, and plan and design our infrastructure to the magnitude of the hazard, the amount of money available, and the benefits that would accrue as compared to the initial and recurring costs in the life of the structure. This is risk management. Even though the hazard gets modified within the small area of influence of the structure after the structure is built to counteract it, major natural hazards in the wider area of general instability/ marginal stability can hardly be modified. Therefore, it is not the hazard that we normally try to manage but it is the risk that we have to manage.

Since engineering is essentially an exercise dictated by the level of investment, the availability of money, and the recovery of costs or the return on investment over normally 15 to 20 years, most of the risk management has to be viewed from this time horizon even though the damage to the environment from the structures has to be considered for a much longer time horizon to avoid irreversible impacts. This does not mean that we can afford to have the hazard increased after such a period. The aim is to ensure that the human activities do not enhance or accelerate the natural process and increase the hazard while we build the infrastructure such that it costs minimum and serve the intended purpose without uncertain failures. Therefore, from economic considerations, the accuracy of costing is crucial. The accuracy of prefeasibility and feasibility costing is the function of the accuracy of hazard assessment and the capability to avoid, or counteract this hazard. It is the geologist who should understand the need of the engineer and assess the temporal and spatial hazards, and it is the engineer who should be able to understand the process of nature and utilise this information to assess and manage the risk. This requires the ability to link the hazard with the damages to the structure of various types, should the hazard occur, and either select or develop appropriate design of the structure to withstand these hazards for at least the time permitted by the economic design life or select an affordable level of risk and build it into the cost.

Engineers and geologists are often confused and use the term hazards and risks interchangeably. In many 
instances, the treatise on hazard and risk assessment is more academic than of practical value. Though numerous methods of assessment and mapping of landslide susceptibility and natural hazards have been dealt by geologists, very few have linked the hazards to the risks in quantifying the overall impact on the cost and life of the engineering structures particularly linear infrastructures such as roads and canals.

In order for the knowledge of science and engineering to be of value to human quality of life, geologists and engineers must at least be able to speak a common language that permits understanding of the processes of the earth; translating these into forces acting upon the intended structures, and the strength of materials constituting the structure and the foundation upon which it rests; and designing the structure to resist the forces over the economic life of the structure.

When more information on the geological, geomorphological, and engineering properties of the material characteristics is ascertained at the detailed design stage, further reductions in the risks to and from the proposed structure is possible at the construction stage.

Mountain Risk Engineering(MRE) programme developed and conducted in 1988-1992 by the International Centre for Integrated Mountain Development in Nepal was a major step forward in creating comprehensive and systematic approaches and techniques for mountain road engineering. The MRE Handbooks (Deoja et al. 1991) cover subject background and applications in two volumes. The entire aspect of mountain-specific road engineering from feasibility to construction and maintenance are presented in a comprehensive manner in approximately 1000 pages of the compilations. Socio-economic appraisals, hazard and risk assessment, environmental impact assessment, slope stability assessment and analysis, landslide analysis and control, bioengineering applications, geometric designs, pavement designs, retaining wall designs, and drainage designs are all covered in the handbook. Based upon such core material, a village-level MRE needs to be developed to create awareness on geological hazards and to develop mountain-specific designs at the rural level.

Overseas Road Note 16 (1997) and several other publications on green roads and biotechnical stabilisation are the result of the experiences and awareness from mountain road constructions in Nepal.

About $80 \%$ of Nepal's area comprises steep and fragile mountainous terrain, and it is natural that such developments in mountain-specific engineering should occur here. Social considerations, development paradigms, terrain compulsions, investment constraints, maintenance burdens, marginal economic activities, and environmental degradation from deforestation, soil loss, landslides, and sedimentation are the factors that determine the appropriateness of the engineering of infrastructures in the mountainous regions. Mountain infrastructural engineering, therefore, requires a comprehensive treatment from multi-disciplinary approaches. The understanding of slopes and their formations and the material forming the slopes is fundamental to further developments of mountain infrastructural engineering. Greater interactions, nationally and internationally among civil engineers, geologists, geotechnical engineers, and engineering geologists shall lead to further enhancement in the quantity and quality of works in this direction. The mountain-specific approaches and techniques developed from the experiences of Nepal shall be useful to the other mountainous regions of the world.

\section{DEFINITION OF HAZARD AND RISK}

Varnes (1984) defines, "Natural hazard is the probability of occurrence within a specified period of time and within a given area of a potentially damaging phenomenon"

Einstein (1988) defines hazard as "Probability that a particular danger occurs within a given period of time". Danger is an existing or potential phenomenon such as landslide, creep, rock fall, debris flow, mudflow, and undercutting.

Varnes (1984) defines risk in terms of specific risk and total risk. "Specific risk, Rs is the expected degree of loss due to a particular natural phenomenon $=$ hazard $\mathrm{x}$ vulnerability", where, "Vulnerability means the degree of loss to a given element or a set of elements at risk resulting from the occurrence of a natural phenomenon of a given magnitude". It is expressed in a scale from 0 (no damage) to 1 (total loss). "Total risk, Rt means expected number of lives lost, persons injured, damage to property, or disruption of economic activity due to a particular natural phenomenon, and is therefore the product of specific risk (Rs) and element at risk (E)" Rt $=\mathrm{Rs} \times \mathrm{E}=\mathrm{H} \times \mathrm{V} \times \mathrm{E}^{\prime \prime}$

Einstein (1988) defines risk as "Hazard x potential worth of loss, $\mathrm{R}=\mathrm{P}[$ Danger $] \mathrm{x} \mathrm{u}(\mathrm{x})$ " or otherwise expressed "probability of an event times the consequences if the event occurs". The danger can be any event that may cause damage, and hazard assesses the probability that this danger may materialise. The probabilities can be obtained through an objective statistical data collection or through a subjective estimation in form of a degree of belief.

In many instances, hazards and risks are taken as synonymous due to the fact that risks are implicit and assumed proportional to the hazards, the relative levels are adequate for comparison purposes, and the quantification of the physical and monetary value is not considered necessary.

\section{TYPES OF HAZARD AND RISK}

Hazards are classified as relative, absolute, empirical, and monitored. Relative hazard is expressed as high, medium, and low. Absolute hazard is expressed in terms of factor of safety deterministically and in terms of probability from probabilistic approach. Hazards expressed in terms of the height and the slope angle based on practical studies of slope failures for different types of soil and moisture 
conditions are empirical hazards. Monitored hazards are expressed in terms of deformation and rate of movement.

Risks may be classified as physical risk, economic risk, and monetary risk depending upon how it is perceived, expressed and communicated. "Loss of $50 \%$ of road/canal due to a deep-seated rotational soil slide, loss of $10 \mathrm{~km} \mathrm{road} /$ canal due to debris flow, and total failure of a retaining wall/ culvert/dam due to rock slides" are examples of expressing risks physically. "The landslide failure at km 5+100 will washout 50 houses and kill 200 people at $500 \mathrm{~m}$ below the road is an expression of risks to human lives". "The landslide results in the failure of the road, canal, or bridge which requires US $\$ 100,000$ worth of rehabilitation" is an example of expressing risks in monetary terms. "There is a 90 per cent probability that the economic rate of return in a road project is 15 per cent" is an example of expression of economic risk.

\section{LEVELS OF HAZARD AND RISK ASSESSMENT}

A short description of hazard and risk assessment at different stages of a project is given below.

\section{National level, regional level, or preliminary planning}

Small-scale maps are useful for preliminary planning at the macro level. A 1: 1,000,000 or smaller, hazard map shall be useful to have some idea of indicative risks of locating major projects at different locations of the country. The hazard maps for such purposes may be prepared by overlaying hazard maps of tectonic/seismic hazards, rainfall hazards, and slope hazards only. For regional level planning for a basically mountainous country like Nepal a 1:50,000-scale map shall be useful.

\section{Project level, prefeasibility level, or planning}

To make preliminary comparisons of alternatives and to determine the rigour of further investigations of the proposed sites existing hazard maps of 1:50,000 or larger scale may be used. If the regional hazard maps are not available, hazard maps may be prepared by overlaying the seismicity map, rainfall map, existing landslides map, land use map, geological map, and the terrain maps of 1:50,000 scale. These maps prepared by desk works should be verified at site by walkover survey. Alternatively, strip maps of the proposed corridors with the help of topographical map, geological map, air photo, and walkover survey can be prepared to indicate the geomorphic, land use, and engineering geological features within the watershed area influencing the alignment. Relative hazards can be assessed from the subjective rating assigned to different characteristics such as slope, soil type and depth, lithology, structure, relief, land use, drainage, rainfall, and existing landslides and erosion. No risk mapping shall be necessary at this stage. Hazard may be taken as synonymous to risk at this stage. The additional costs of the structure due to the hazards may be incorporated through certain factors depending upon the per cent of road under major and medium hazards.
A simplified approach to direct assessment of hazards and risks may be followed by dividing the alignments under study in 1:50,000 to $1: 25,000$ scale topographical maps, into one $\mathrm{km}$ sections and indicating by field surveys rock or soil, existing dangers (landslides, debris flow, major gullies, major erosion-prone areas, and river undercutting), and potential dangers. Probability may be assigned to each type of potential failure and the extent of damage to the proposed design type structure, if the danger should occur after the structure is built, by subjective judgment of the engineering geologists and engineering experts involved in the survey.

\section{Project level, feasibility stage, or hazard assessment}

The assessment of both hazards and risks shall be necessary at the feasibility stage studies because the cost estimation at about $+10 \%$ accuracy to be done at this stage requires development of indicative designs as well. The scale of the hazard map or other related direct maps such as geological map, landslide distribution map, slope map, air photos and rainfall map shall be $1: 25,000$ to $1: 10,000$. For rapid assessment of hazards, the desk works from the available maps and air photo can be quickly verified or new engineering geological and geomorphologic maps can be prepared along the strip or corridor influencing the structure from field walkover surveys. It is necessary to understand the effect of the type and magnitude of hazard on the type and size of the structure to assess risks from the hazards. The frequency and magnitude of the hazards and their relationship with risk can be determined from subjective assessments.

\section{Detailed design stage}

The scale of map has to be much larger for detailed design stage of a project. The feasibility stage assessments can be adequate for low hazard areas and no hazard areas. But for high hazard areas, a large scale (i.e., 1: 2,000 to 1: 10,000) mapping shall be needed to indicate engineering geological and geotechnical details and allow slope stability analysis and determination of factor of safety. Hazards are so modified by the counter measures that there are no or negligible hazards after it and thus no risks. There may be situations that it will not be possible to modify the hazard by the structure but the structure needs to be constructed anyway. Acceptance and understanding of the risks will help to monitor and take precautions to avoid risks to life and further economic activities within the influence area. It will also assist in maintenance planning and realistic costing of projects over the analysis life. Risks can also be avoided by avoidance of hazard that is avoiding structures, investment, and life or property from the hazard area and the area within its influence.

\section{HAZARD ASSESSMENT METHODS}

The following discussion briefly explains the methods for assessment of hazards for feasibility level works of a given project. These methods are not normally justified for prefeasibility studies because of the amount of work involved. 
The users may also develop their own method based upon these concepts to suit their particular nature of works.

\section{Romana (1988), Slope Mass Rating (SMR) for rock slopes}

It is based on Bieniavski's rock mass rating (Bieniavski 1976) and adjustment factors for dip direction, dip amount, and method of blasting.

$\mathrm{SMR}=\mathrm{RMR}-(\mathrm{F} 1 \times \mathrm{F} 2 \times \mathrm{F} 3)+\mathrm{F} 4$

where, RMR is rock mass rating, having a total range of 0 to 100 , computed according to Bieniavski (1976) proposal adding rating values for five parameters: strength of intact rock, RQD rock quality designation (measured or estimated), spacing of discontinuities, condition of discontinuities, and water inflow through discontinuities; and F1, F2, F3 are adjustments for joints and F4 is adjustment for method of excavation. Different types and extent of failure are predicted from the limits of SMR, slope mass rating as follows:

- Plane failure: none for SMR value $>60$, big for MR 40-5, and major for SMR 15-40.

- Wedge failure: none for SMR $>75$, some for SMR value 60-75, many for SMR 40-55, and none for SMR 15-40.

- Toppling failure: none for SMR > 65, minor for SMR 50-65, major for SMR 20-35.

- Soil-like failure: none for SMR $>30$, possible for SMR 10-30.

Rock slope hazard map may be prepared upon the relative values assigned to the type and extent of failure calculated as above.

\section{Deoja and Thapa (1989), soil slope hazard}

Soil slope movement hazard rating is given by,

$$
\mathrm{H}=\mathrm{D}[(\mathrm{R}+\mathrm{Hw})(\mathrm{S}+\mathrm{C})+(\mathrm{I}+\mathrm{L})]
$$

where, $\mathrm{H}=$ hazard value, $\mathrm{D}, \mathrm{R}, \mathrm{Hw}, \mathrm{S}, \mathrm{C}, \mathrm{I}, \mathrm{L}$ are weightages for depth of soil, rainfall, depth of water table, soil type, complexity, slope, and land use, respectively. The level of hazard is low for $\mathrm{H}=0-30$, medium for $\mathrm{H}=31-50$, and high for $\mathrm{H}>50$ and the extent of damage depends upon the hazard level and the type of the existing instability phenomenon such as debris flow, deep-seated slide, shallow slide, glacier lake outburst flood (GLOF), landslide dam, undercutting by river or streams, and earthquake. The weightages for different hazards are given below:

- Depth of soil in $\mathrm{m} /$ weightage: $0-0.9 / 0,1-5 / 1.5$, 6-10/2, 11-15/3, 15-20/2.5, >20/2;

- Rainfall in $\mathrm{m} /$ weightage: $0-0.4 / 0.5,0.5-2 / 1,2-3.5 / 1.2$, $>3.5 / 1.5$;

- Depth of water table from surface in $\mathrm{m} /$ weightage: $0-0.4 / 2.5,6-10 / 2,11-20 / 1.5 ;>20 / 0$

- Soil characteristics/weightage: GW, GP, SW, SP/0.5, GM, SM/1, GL, SL/2, ML, CL, OL/2.5;

- Complexity/weightage: Strong dissection/1.5, moderate dissection $/ 0.75$, simple dissection $/ 0.25$;
- Slope angle in degrees/weightage: $0-14 / 1,15-24 / 3$, $25-34 / 5,35-54 / 7,45-54 / 7,55-60 / 8,>60 / 8$; and

- Land use/weightage: forest/3, pasture/5, un-irrigated cropping/5, irrigated cropping/8.

Existing instabilities (dangers) such as debris flow, deepseated slides, GLOF, landslide dam, major undercutting by river, and high seismicity are regarded as high hazard.

Soil hazard maps may be prepared based upon the relative hazard values calculated as above.

\section{Gupta and Anbalagan (1997)}

The area to be hazard mapped is divided into numerous facets and the maps such as facet map, structural map, land use and land cover map, relative relief map, lithological map, and slope morphometry map, hydrogeological condition map are prepared from existing maps and field surveys and the ratings as per the limits given are assigned. These maps are overlaid and the hazard map is prepared from the sum total scores.

\section{TRRL Overseas Road Note 16 (1997)}

Relative hazards are assessed by landslide hazard mapping (LHM) which is based upon a series of factor maps derived from 1; 25,000 scale air photos, 1:50,000 scale topographical maps, and 1:200,000 scale geological maps; and the comparison of observed density of landslides in each factor category with those expected had there been no control on the distribution of slope failure. The factor maps are Landslide Distribution and Underlying Geology Map, Slope Physiographic Classification Map, Slope Angle Distribution Map, Slope Aspect Distribution Map, Landuse Distribution Map, and Summary of Landslide Hazard Zones Map.

\section{Einstein (1988), landslide risk assessment procedure}

This method presents a formal procedure for hazard and risk assessment and involves preparation of state-of-nature (SN) map, danger map, hazard map, and risk map. The first level map, the state-of-nature map, is prepared from topographical map, geological map, vegetation map, hydrological map, geotechnical map, test results, displacement measurements, water level observations, and visual observations. The second level map, danger map, is prepared by inventorying existing and potential slope instabilities. The third level map is the hazard map, which maps the danger and its probabilities of occurrence. The fourth level map is the risk map, which shows hazard and its potential consequence. The fifth level is the management of risk. The calculation of hazard in this method involves probability calculations from the several data in the stateof-nature and danger maps.

Simplified method recommended for linear infrastructure, based upon method of Einstein (1988) and Deoja et al. (1991)

The method utilises the concept of formal risk assessment method suggested by Einstein (1988), which involves five level mapping/assessments namely state-of-nature mapping, 
danger inventorying/mapping, hazard mapping/ determination, risk assessment, and landslide management.

\section{Level 1: Assessments/mapping for state-of-nature}

A simplified method of quantifying various attributes of the geological and topographical features of a geological facet or a watershed area influencing the road or the structure in question into a combined rating of the state-of-nature in the 0 to 1 scale through pre-assigned ratings to the several attributes of terrain, land use, lithology, and geologic structures have been adopted. Table 1 is suggested for the listing of the various parameters of the state-of-nature and their values. The weightages for various attributes in this table are assigned on the basis of experience and judgment. These weightages may be adjusted for specific conditions based upon experience or research. The main advantage of such rating is that it allows characterisation of the various attributes into a combined value that indicates the criticality of the state-of-nature.

\section{Level 2: Assessments/mapping for danger}

This is an inventorying of existing or potential (imminent) dangers (instabilities) such as erosion, gullies, debris/mud flow, undercutting, and landslides including their geometry and impact area in the facet or the watershed area identified in Level 1 assessments above. Table 2 is suggested for data collection. Danger map showing all these features shall be prepared in the same scale as state-of-nature map. The imminent danger is to be identified from the site conditions but there is no prediction at this stage. This map shall assist in predicting the future dangers. The existence of a shallow soil slide in a given geologic facet or unit in the watershed influencing the road or any other proposed structure implies that the probability of occurrence of shallow slide in such areas is one and since the area of landslide may only be a fraction of the total area of the facet, the probability that the danger (shallow soil slide) covers the entire area of the facet is not one. This allows the adjustments for the uncertainty of non-homogeneity of the state-of-nature (SN) in the facet. The area of existing danger/slide as a percentage of the total area of the facet may provide some indication of this probability.

\section{Level 3: Assessments of hazards}

The assessments of hazards, that is the prediction of certain type of danger in a certain area over a certain period of time, is made from the value of the state-of-nature and the existing and imminent dangers, their type, size and geometry. Tables 3 and 4 are suggested for prediction of dangers and their probabilities that is the hazards. Hazards after road, if the technology adopted is going to alter the conditions, may also be estimated to indicate the effect of road cuts or toe supports from road structures. Road activity does not always increase the hazard. Sometimes, the road cut into the rock may remove shallow slides, minor failures, or more unstable inner layers, and thus reduce the hazard. The road technology to be considered as a base case for the determination of hazards after the road, under unmitigated conditions, is the conventional low cost and leastdisturbance method. Such method does not normally involve modification of the hazard before the road construction. This simplifies the task of probability assignment.

\section{Level 4: Risk assessments}

Risks in terms of the type and extent of damage to the road and the area of the facet are calculated as per Table 5 . The facet defines the spatial limits and the analysis period defines the temporal limits. There may be triggers such as heavy rainfall and improper road cuts or landslide removals more than once during the 15 to 20 year analysis periods but for the purpose of simplification one time failure only is considered. It is up to the experience of the evaluator to estimate the values of minor failure and major failure. Minor soil slides or rock slides above the road cut may cause minor damages to the road such as damages to side drains and pavement layers only while major slides above the road cut or slides with failure surface encompassing the entire road may cause full damage to the road section. For example, a minor danger/failure covering $1 \mathrm{~m}$ length of road may be assigned ten per cent of the average total cost of $1 \mathrm{~m}$ length of the road while major danger may entail hundred per cent cost of the road for the length affected. Besides, there may be other risks such as loss of land, damages to houses, and injury or death of men and animal in the influence zone of the danger. These are serious risks in highly populated areas and in high value lands.

\section{Level 5: Risk management}

Once risks are determined in terms of the monetary value of the loss of road and loss of land, life and property, for the base case technology, there are several options. Living with the risks, avoiding the risks by change of hazardous sections of the alignment, reducing the risks by low investments through reduced standards of road in the hazardous sections, removing the hazards by removal of unstable material, providing active countermeasures such as retaining wall, buttresses, vegetation and plantations, and other soil and rock reinforcements are the possible options. Decisionmaking involves the comparison of total costs of these options and selecting the least cost option.

The steps involved in assessing hazards and risks for linear infrastructure such as roads is outlined below:

1. Collect available geological, topographical, land use maps, and air photos of 1:50,000 scale, preferably $1: 25,000$ or larger scale.

2. Mark the proposed alignment on the maps.

3. Divide the topographical map into facets or watershed areas affecting the alignment and or to be affected by alignment up-slope and down-slope of the alignment.

4. Trace the facet map into other maps, identify, and record the various parameters of the state-of-nature, and existing and potential dangers in these maps or in a fresh base map.

5. Assess value of the state-of-nature for each facet using the previous tables or by the experienced guess at site.

6. For each facet, note the existing and potential dangers, their geometry, size, and length of road influenced, and other property affected or likely to be affected. 


\begin{tabular}{|c|c|c|c|c|c|c|c|c|c|c|c|c|c|}
\hline & Guppy & & & 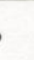 & & & & g. & & & $\stackrel{0}{0}$ & & \\
\hline & 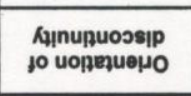 & & inbul & & & & & $\begin{array}{l}\text { sit } \\
\text { uluol } \\
\text { dols } \mathrm{d}\end{array}$ & & & $\begin{array}{l}\text { Sueq } \\
\text { ofs dic }\end{array}$ & & \\
\hline & Gupey & 。 & & & סֶ: & & ذั & & 8 & & & & \\
\hline 2 & Gujəeds zulor & हैं & & & $\div 8$ & & 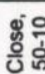 & & 蒙宫 & & & & \\
\hline 递 & Bupey & 。 & ס. & & ( & & & & & & & & \\
\hline $\begin{array}{l}\frac{6}{0} \\
\frac{5}{9}\end{array}$ & өред6 биреиреем & 密 & & & & & & & & & & & \\
\hline & Guppey & & $\circ$ & & & & 范 & 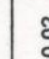 & s. & : & 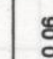 & 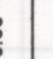 & \\
\hline & $\operatorname{ed} K_{1}$ & & & & & & (1600: & & & 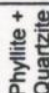 & 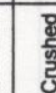 & 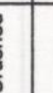 & \\
\hline & xоо & & els!! & & & & tewe: & & 응 & $\frac{\vec{E}}{4}$ & 总 & 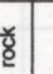 & \\
\hline & Gupey & & & & & $\frac{5}{5}$ & : & & & & & & \\
\hline & w' 'updep ॥OS & $\bar{v}$ & & & $\frac{1}{i}$ & & $\AA^{2}$ & 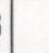 & & & & & \\
\hline$\overline{\bar{\sigma}}$ & Bupey & $\begin{array}{l}\text { ơ } \\
0 \\
0\end{array}$ & & i & & $\begin{array}{l}\text { o. } \\
0 \\
\dot{0} \\
0 \\
0\end{array}$ & & $\begin{array}{l} \\
0 \\
0 \\
0 \\
0 \\
0\end{array}$ & 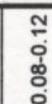 & & 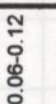 & 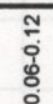 & \\
\hline & ed/4 ॥OS & $\underset{\text { wedu }}{\text { wnin }}$ & & & E & $\sum_{\bar{n}}^{\vec{z}} \varepsilon$ & & $\frac{\bar{s}}{\bar{n}}$ & $\stackrel{\frac{2}{\pi}}{\pi}$ & & & n & \\
\hline & Gupey & $\stackrel{0}{0}$ & & ?: & \pm & & & & & & & & \\
\hline 居 & $\begin{array}{c}\text { w' 'peod } \\
\text { woy eวuęs|a }\end{array}$ & 员 & & & : & & & & & & & & \\
\hline & Guppey & 。 & & 0 & 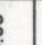 & ?ִ & 8 & & & & & & \\
\hline 岂 & $\operatorname{\theta d} \alpha_{1}$ & 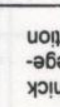 & & 苋 & & & 吨 & & & & & & \\
\hline & Buppey & 。 & ర్ర & ¿ & 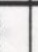 & & & & & & & & \\
\hline . & 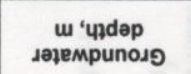 & ટે & گँ & 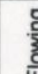 & & & & & & & & & \\
\hline 犃 & Gupey & ○ & İ & g & 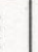 & & & & & & & & \\
\hline & 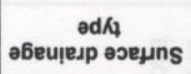 & $\frac{\mathscr{0}}{\frac{E}{D}}$ & 结 & ह్ & 递 & & & & & & & & \\
\hline & Guppey & 。 & & & 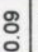 & 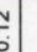 & & & & & & & \\
\hline 言 & 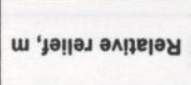 & \% & & & & 3 & & & & & & & \\
\hline : & Gupey & * & & o. & 0 & & & & 1 & : & \begin{tabular}{c}
$\square$ \\
\hdashline \\
\end{tabular} & & \\
\hline & seaد6əp 'edo|S & कू & & & & & & 要 & D & $\frac{1}{4}$ & & & \\
\hline
\end{tabular}



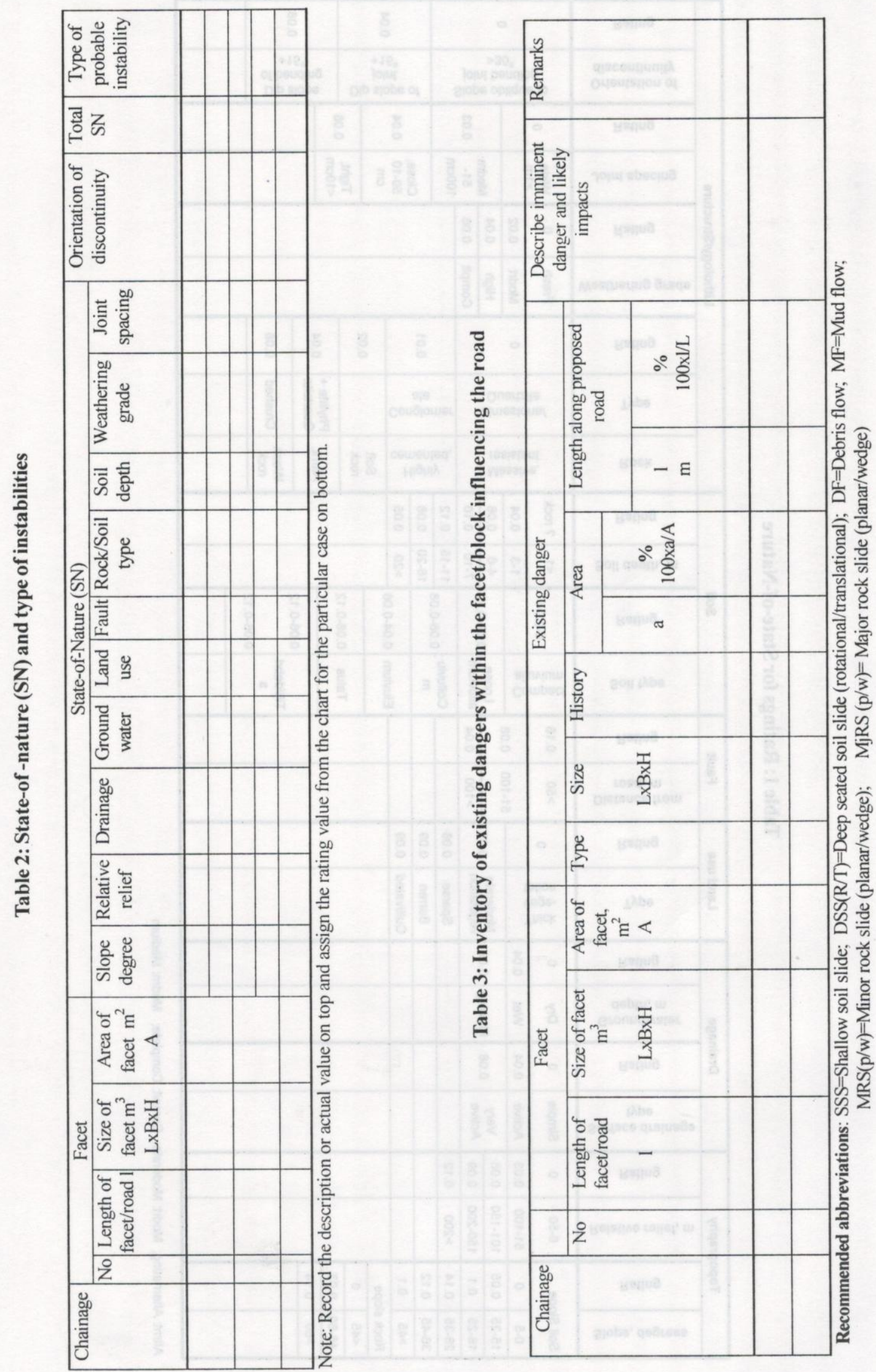
Mountain roads development in Nepal
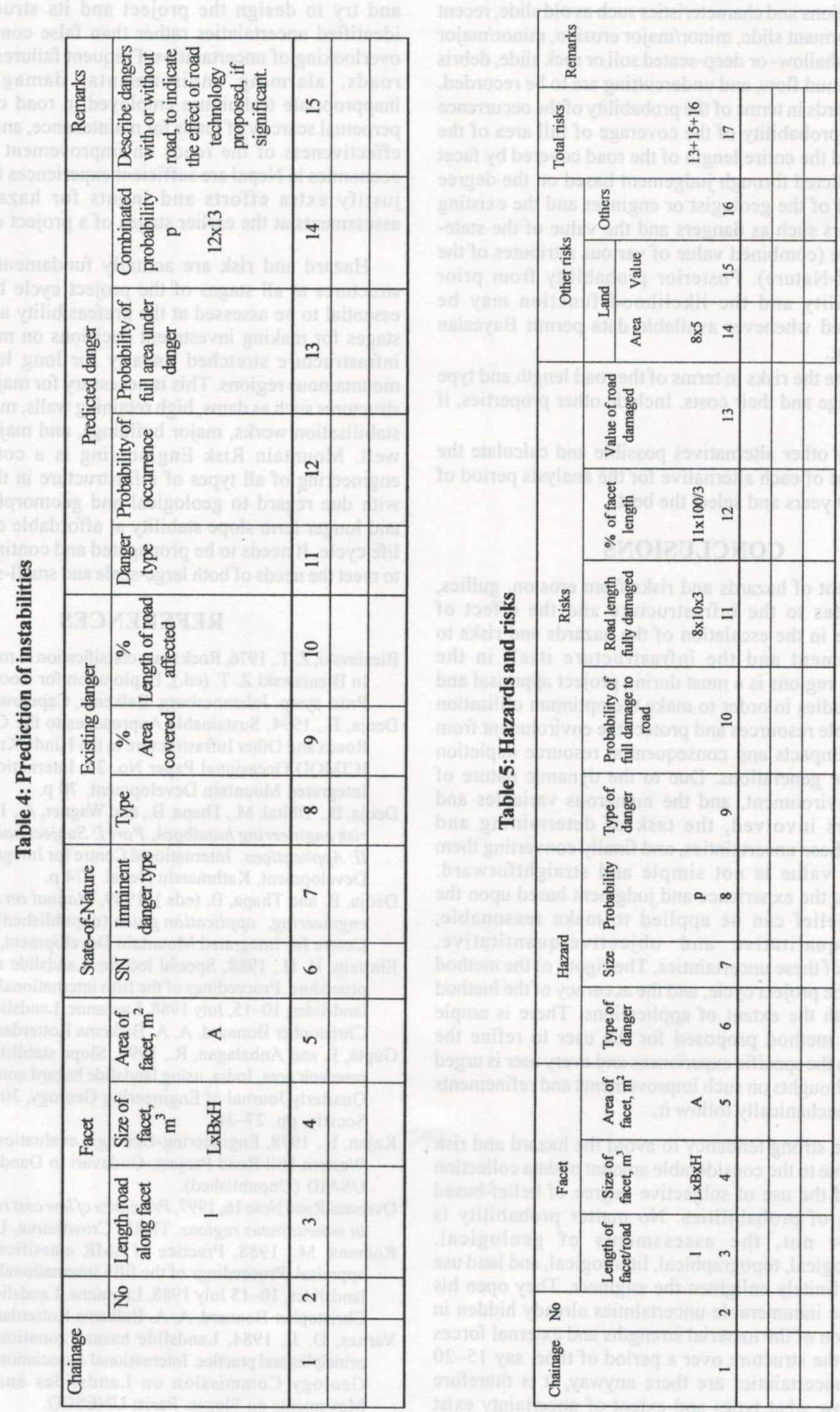
Descriptions and characteristics such as old slide, recent slide, dormant slide, minor/major erosion, minor/major gullies, shallow- or deep-seated soil or rock slide, debris flow or mud flow, and undercutting are to be recorded. The hazards in terms of the probability of the occurrence and the probability of the coverage of full area of the facet and the entire length of the road covered by facet are predicted through judgement based on the degree of belief of the geologist or engineer and the existing indicators such as dangers and the value of the stateof-nature (combined value of various attributes of the State-of-Nature). Posterior probability from prior probability and the likelihood function may be calculated whenever available data permit Bayesian updating.

7. Calculate the risks in terms of the road length and type of damage and their costs. Include other properties, if any.

8. Identify other alternatives possible and calculate the total cost of each alternative for the analysis period of 15 to 20 years and select the best.

\section{CONCLUSIONS}

Assessment of hazards and risks from erosion, gullies, and landslides to the infrastructure and the effect of infrastructure in the escalation of the hazards and risks to the environment and the infrastructure itself in the mountainous regions is a must during project appraisal and feasibility studies in order to make the optimum utilisation of the available resources and protect the environment from irreversible impacts and consequential resource depletion for the future generations. Due to the dynamic nature of mountain environment, and the numerous variables and uncertainties involved, the task of determining and quantifying these uncertainties, and finally converting them into money value is not simple and straightforward. Nevertheless, the experience and judgment based upon the degree of belief can be applied to make reasonable, subjective-qualitative and objective-quantitative, assessments of these uncertainties. The rigour of the method depends on the project cycle, and the accuracy of the method increases with the extent of applications. There is ample room in the method proposed for the user to refine the methods with the specific experiences and every user is urged to put some thoughts on such improvements and refinements rather than mechanically follow it.

There is a strong tendency to avoid the hazard and risk assessment due to the considerable amount of data collection involved and the use of subjective degree of belief-based assessments of probabilities. No matter probability is assessed or not, the assessments of geological, geomorphological, topographical, lithological, and land use attributes definitely enlighten the engineer. They open his eyes as to the innumerable uncertainties already hidden in his assumption of the material strengths and external forces acting upon the structure over a period of time, say 15-20 years. The uncertainties are there anyway, it is therefore better to know what types and extent of uncertainty exist and try to design the project and its structures under identified uncertainties rather than false confidence from overlooking of uncertainties. Frequent failures of high-cost roads, alarming environmental damage from the inappropriate techniques employed in road constructions, perpetual scarcity of funds for maintenance, and the minimal effectiveness of the roads on improvement of mountain economies in Nepal are sufficient experiences from Nepal to justify extra efforts and inputs for hazard and risk assessments at the earlier stages of a project cycle.

Hazard and risk are actually fundamental to all the structures at all stages of the project cycle but it is most essential to be assessed at the prefeasibility and feasibility stages for making investment decisions on major types of infrastructure stretched linearly for long lengths in the mountainous regions. This is necessary for major point-type structures such as dams, high retaining walls, major landslide stabilisation works, major buildings, and major bridges as well. Mountain Risk Engineering is a comprehensive engineering of all types of infrastructure in the mountains with due regard to geological and geomorphic processes and longer term slope stability at affordable costs over the life cycle. It needs to be propagated and continually refined to meet the needs of both large-scale and small-scale projects.

\section{REFERENCES}

Bieniavski, Z. T., 1976, Rock mass classification in rock engineering. In Bieniawski Z. T. (ed.), Exploration for Rock Engineering, Proc. symp. Johannesburg. Balkema, Capetown, pp. 97-106.

Deoja, B., 1994, Sustainable Approaches to the Construction of Roads and Other Infrastructure in the Hindu Kush-Himalayas, ICIMOD Occasional Paper No. 24, International Centre for Integrated Mountain Development, $70 \mathrm{p}$.

Deoja, B., Dhital, M., Thapa, B., and Wagner, A., 1991, Mountain risk engineering handbook, Part I: Subject background, Part II: Applications. International Centre for Integrated Mountain Development, Kathmandu Nepal, 874 p.

Deoja, B. and Thapa, B. (eds.), 1989, Manual on mountain risks engineering, application guide (unpublished). International Centre for Integrated Mountain Development, v. 2a, 120 p.

Einstein, H. H., 1988, Special lecture: Landslide risk assessment procedure. Proceedings of the fifth international symposium on landslides, 10-15, July 1988, Lausanne, Landslides, and editor: Christopher Bonnard, A. A. Balkema Rotterdam, v. 2, 1075 p.

Gupta, P. and Anbalagan, R., 1997, Slope stability of Tehri dam reservoir area, India, using landslide hazard zonation mapping. Quarterly Journal of Engineering Geology, 30, The Geologic Society, pp. 27-36.

Kojan, E., 1978, Engineering-Geologic evaluation of landslides, Western Hill Road Project, Godavari to Dandeldhura Nepal, USAID (Unpublished).

Overseas Road Note 16,1997, Principles of low cost road engineering in mountainous regions. TRRL, Crowthorne, U.K., 498 p.

Romana, M., 1988, Practice of SMR classification for slope appraisal. Proceedings of the fifth international symposium on landslides, 10-15 July 1988, Lausanne. Landslides, and editor: Christopher Bonnard, A. A. Balkema Rotterdam, v. 2, 1227 p.

Varnes, D. J., 1984, Landslide hazard zonation. A review of principles and practice. International Association of Engineering Geology Commission on Landslides and Other Mass Movements on Slopes. Paris: UNESCO. 